\title{
Isolated thoracic perfusion with chemofiltration for progressive malignant pleural mesothelioma
}

This article was published in the following Dove Press journal:

OncoTargets and Therapy

19 June 2017

Number of times this article has been viewed

\section{Karl Reinhard Aigner \\ Emir Selak \\ Sabine Gailhofer}

Department of Surgical Oncology, Medias Klinikum, Burghausen, Germany
Correspondence: Karl Reinhard Aigner Department of Surgical Oncology, Medias Klinikum GmbH \& Co KG,

Krankenhausstraße 3a, 84489

Burghausen, Germany

$\mathrm{Tel}+49867791600$

Fax +49 $86779160 \quad 120$

Email info@prof-aigner.de
Introduction: Therapy of malignant pleural mesothelioma and especially the adequate role of surgery in this context remain the subject of controversial discussions. Radical surgery in particular, which is associated with substantial morbidity, failed to translate into a definite survival advantage. We report on interim results of an ongoing Phase II study of regional chemotherapy in terms of isolated thoracic perfusion with chemofiltration (ITP-F).

Patients and methods: Twenty-eight patients ( 25 male, 3 female, mean age 63.4 years) with advanced pleural mesothelioma were included in this study. Isolation of the chest was achieved by insertion of a venous and arterial stop-flow balloon catheter via a femoral access. The aorta and inferior vena cava were blocked at the level of the diaphragm and the upper arms were blocked by pneumatic cuffs. Chemotherapy, consisting of $60 \mathrm{mg} / \mathrm{m}^{2}$ cisplatin and $15 \mathrm{mg} / \mathrm{m}^{2}$ mitoxantrone, was administered directly into the aorta. The isolated circuit was maintained for 15 minutes followed by $\sim 45$ minutes of chemofiltration with a hemoprocessor until $5 \mathrm{~L}$ of filtrate were reached. The endpoints of the study were overall survival and quality of life (QoL).

Results: Out of 28 patients enrolled in the study, 5 had prior surgeries, 10 patients had systemic chemotherapy, and 5 patients additional irradiation. In all patients in restaging, clinical progress was noted. In all, 162 cycles were administered. Due to chemofiltration, toxicity was within tolerable limits, revealing World Health Organization grade I leucopenia and thrombocytopenia in 9 patients and mucositis grade I in 6 patients. The major surgical complication was inguinal lymphatic fistula in $40 \%$ of the cases. Gastrointestinal toxicity and/or neurotoxicity were never observed. One-year survival was 49\%, 2-year and 3-year survival was 31\%, and 5-year survival was $18 \%$. Median overall survival was 12 months and progression-free survival 9 months.

Conclusion: ITP-F for patients with advanced pleural mesothelioma, progressive after standard therapies, is an effective and well-tolerated treatment modality, offering comparably long survival data at a good QoL.

Keywords: regional chemotherapy, isolation perfusion, mesothelioma, intra-arterial chemotherapy, stop flow, locally advanced cancers, thoracic malignancies

\section{Introduction}

Malignant pleural mesothelioma (MPM) is commonly considered a tumor with a dismal prognosis, nonresponsive to any kind of chemotherapy. Surgical approaches such as pleurectomy and decortication or extrapleural pneumonectomy (EPP) are rarely curative and entail recurrences. It remains questionable whether or not patients benefit from extensive surgical interventions in terms of survival and quality of life (QoL). ${ }^{1}$ Combination therapies consisting of surgery, chemotherapy, and irradiation also had no substantial effect on the outcome in terms of improvement of symptoms and survival. ${ }^{2}$ Early stage I cases only seem to benefit from radical surgery. ${ }^{3}$ 
The reason for the poor therapeutic outcome so far is considered to be chemoresistance of the tumor itself and its biologic behavior, revealing a typical growth pattern with extended invasion of parietal and visceral pleura throughout the pleural cavity and finally invasion of the thoracic wall, mediastinum, and lungs. ${ }^{4}$ The vast majority of patients suffering from mesothelioma have a history of asbestos exposure some 3-4 decades prior to the onset and diagnosis of the disease. ${ }^{5}$ This explains why men are affected by far more than women and the median age is $\sim 65$ years. ${ }^{6}$

The lack of effective life-prolonging therapies in this mostly advanced disease justifies palliative measures just to alleviate discomfort and pain. ${ }^{7}$ In this context, there was a need for a less straining but effective and life-prolonging treatment modality.

High exposure intra-arterial chemotherapy is capable of overcoming chemoresistance of tumor cells and may induce substantial tumor response even if conventional systemic chemotherapy fails. ${ }^{89}$ Furthermore, chemotherapy-related toxicities can be diminished by means of chemofiltration after exposure to the cytotoxic agents. ${ }^{10-12}$

In this respect, we investigated isolated intra-arterial chemotherapy of the chest followed by chemofiltration in pretreated patients following multimodal therapy.

\section{Patients and methods}

Patients with histologically confirmed epithelioid MPM, clinical stage III and IV disease, and prior therapy were eligible after informed consent for this Phase II study. Patients were required to be $>18$ years of age and have a Karnofsky performance status $\geq 60$. Patients were also required to have adequate renal and cardiac function. This study was performed in compliance with the principles of good clinical practice, the Helsinki Declaration, and federal guidelines and had approval by the Medias Institutional Review Committee. Patients with advanced pleural mesothelioma, lacking further treatment options, signed informed consent for isolated thoracic perfusion (ITP) because the alternative option would have been best supportive care.

Twenty-eight patients with histologically proven epithelioid MPM were included in this study. There were 25 male and 3 female patients; mean age was 63.4 years (range 43-86 years). Twenty patients were characterized as stage IV and 8 patients as stage III MPM according to the Union for International Cancer Control staging system. Fifteen out of 28 patients (54\%) had prior therapy in terms of surgery, chemotherapy, or radiochemotherapy; a minority underwent EPP and decortication (5/28; 18\%). Six had video assisted thoracoscopic surgery with pleurodesis. Chemotherapies in 10 patients involved cisplatin and pemetrexed, were in progression, and refused further chemotherapy because of reduced performance. Four patients had received secondline and 2 patients third-line systemic chemotherapy. Five patients (14\%) had received additional conventional radiotherapy between 50 and 56 Gy. All patients demonstrated progress in computed tomography (CT) scan before the study. In $20 / 28$ patients $(71 \%$ ), the recommendation of an interdisciplinary conference (tumor board) was best supportive care due to lack of other therapeutic options. No patient had abdominal, cerebral, or bone metastases. Patient characteristics are summarized in Table 1.

\section{ITP and chemofiltration (ITP-F)}

Regional intra-arterial chemotherapy was performed under general anesthesia and systemic anticoagulation with heparin (Ratiopharm GmbH, Ulm, Germany) at a dose of 150 units/ $\mathrm{kg}$ bodyweight. Following insertion of a venous and arterial $21 \mathrm{ch}$. three-channel stop-flow balloon catheter (PfM, Cologne, Germany) via an inguinal access, the inferior vena cava was blocked beneath the right atrium, and the aorta was blocked at the level of the diaphragm, both under X-ray control. Correct placement of the catheters was documented by cavography and aortography, respectively (Figure 1A and B). The upper arms were blocked by pneumatic cuffs, following which the isolation of the chest, head, and neck area was completed. After hyperoxygenation with a p02 of $100 \%$ by mechanical ventilation, chemotherapy was carried out either manually with high pulsatile pressure against the aortic blood stream through the coaxial channel of the arterial catheter which exits at its tip, or through an additional straight flush aortic catheter. A schematic model of the method is displayed in Figure 2.

Table I Patients characteristics (mean age 63.4 years, range 43-86 years)

\begin{tabular}{lll}
\hline Patients and pretreatments & $\mathbf{n}$ & $\%$ \\
\hline $\begin{array}{l}\text { Patients included } \\
\text { Sex }\end{array}$ & 28 & 100 \\
$\quad$ Male & 25 & 89 \\
$\quad$ Female & 3 & 11 \\
Stage & & \\
$\quad$ III & 8 & 29 \\
IV & 20 & 71 \\
Prior surgery & 5 & 18 \\
Prior chemotherapy & 10 & 36 \\
$\quad$ Cisplatin/pemetrexed & 10 & 36 \\
Second-line chemotherapy & 4 & 14 \\
$\quad$ Third-line chemotherapy & 2 & 7 \\
Prior radiotherapy & 5 & 18 \\
\hline
\end{tabular}



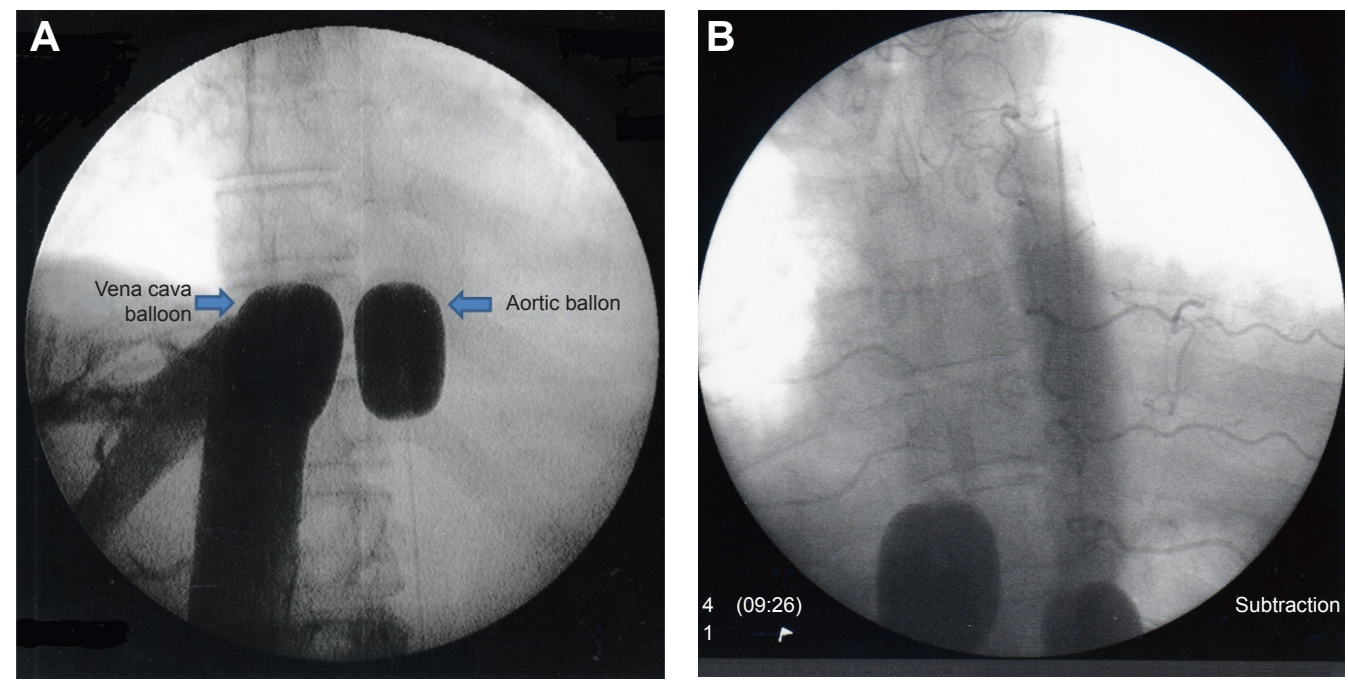

Figure I Cavography and aortography.

Notes: (A) Balloon blocking of aorta and vena cava at the level of the diaphragm.

(B) Intercostal arteries feeding the tumor in the visceral pleura in the aortogram.

After administration of chemotherapy, autochthonous perfusion with the heart as internal pump with blocked stopflow catheters was maintained for 15 minutes. Following de-blocking of both catheters, chemofiltration continued for $\sim 45$ minutes with $5 \mathrm{~L}$ of hemofiltration solution (Duosol containing $4 \mathrm{mmol} / \mathrm{L}$ potassium; B. Braun, Melsungen, Germany) using a Diapact CRRT hemoprocessor (B. Braun) at a maximum flow rate of $500 \mathrm{~mL} / \mathrm{min}$.

After filtration, the catheters were removed and the vascular accesses repaired with $5 / 0$ prolene running sutures. Thereafter, the small incision in the groin was surgically closed over a drain. Skin sutures were removed after the tenth postoperative day.

\section{Pharmacokinetics and pharmacodynamics}

There are two aspects of how to create higher drug exposure as compared with systemic chemotherapy. First, by reducing the circulating blood volume in an isolated circuit, the drug concentration is increased. A volume reduction to one third

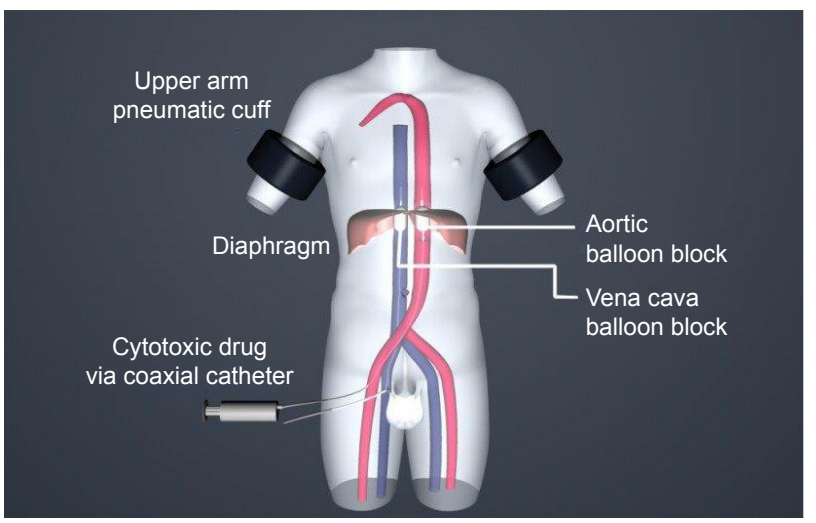

Figure 2 Scheme of isolated thoracic perfusion. or one fourth of the systemic circulation entails an increased drug concentration by a factor of $3-4 .{ }^{8}$ Figure $3 \mathrm{~A}$ demonstrates an example of a systemic bolus of $20 \mathrm{mg}$ mitomycin (Medac GmbH, Hamburg, Germany) versus an intra-arterial injection of the same dose during ITP. The drug levels in the isolated circuit are 3-4 times higher than in the venous system, because of the reduced blood volume. It is worth noting that already after 10 minutes p.i. the intravascular chemotherapy concentrations are nearly at an equal level.

Second, a manual pulsatile injection through the arterial stop-flow catheter generates first-pass concentrations of cisplatin (Medac $\mathrm{GmbH}$ ) of $\sim 70,000-80,000 \mathrm{ng} / \mathrm{mL}$ in the aorta while drug concentrations in the venous system (samples taken at the same time in the vena cava) stay low between 1,000 and 3,000 $\mathrm{ng} / \mathrm{mL}$ (Figure 3B). The rapid elimination of the drug is due to dilution in the systemic blood volume and the so-called first-pass effect in the reduced circuit. After arterial administration of the drug, depending on the arterial blood flow and the total blood volume, 20- to 80-fold increased drug concentrations with correspondingly increased "first-pass uptake" are generated. Using systemic chemofiltration after 15 minutes of stopflow conditions, the injected drugs are reduced by $60 \%$ in the systemic circuit, thus resulting in marked reduction of toxicity directly after therapy as well as a reduction of late cumulative toxicity. ${ }^{10-12}$

\section{Chemotherapy and follow-up}

Administered chemotherapy consisted of $60 \mathrm{mg} / \mathrm{m}^{2}$ cisplatin and $15 \mathrm{mg} / \mathrm{m}^{2}$ mitoxantrone. All 10 patients had previously received platinum systemically. In the isolation perfusion 

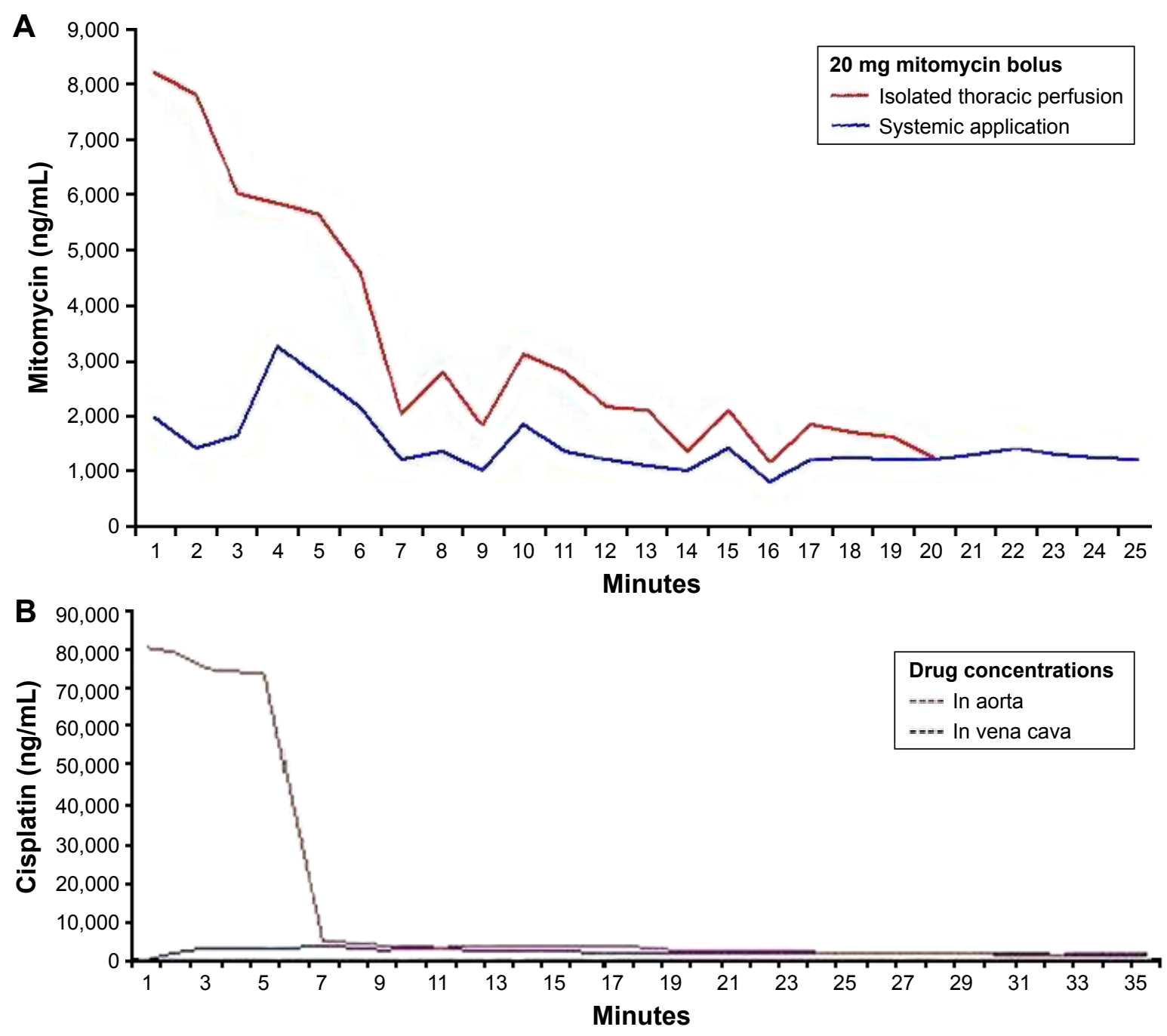

Figure 3 (A) Mitomycin plasma levels in isolated thoracic perfusion with chemofiltration versus intravenous application. Adapted with permission from Springer Nature book. Toxicity profiles with systemic versus regional chemotherapy. Induction Chemotherapy - Systemic and Locoregional, 20I6, 497-506, Aigner KR, Knapp N; ${ }^{7}$ (B) cisplatin plasma levels in the thoracic aorta (dotted line) and in the vena cava (baseline) after intra-arterial pulsatile infusion of $80 \mathrm{mg}$ cisplatin, demonstrating the so-called firstpass effect in intra-arterial chemotherapy. Adapted with permission from Springer Nature book. Toxicity profiles with systemic versus regional chemotherapy. Induction Chemotherapy - Systemic and Locoregional, 2016, 497-506, Aigner KR, Knapp N. ${ }^{7}$

setting, it is administered in high concentrations because of the arterial access. The concentration-dependent effect of mitoxantrone is comparable. The treatment was repeated at 3-week intervals. Restaging was scheduled after each second course of ITP. In case of progressive disease (PD), the therapy was discontinued. In case of response or stable disease in chest CT scan, the treatment was continued until progress of the disease or deterioration of the patient's performance status.

\section{Statistical analysis}

The primary endpoint of the study was overall survival. The secondary endpoint included QoL and progression-free survival (PFS). This was analyzed using Kaplan-Meier methods and was censored at the date of the last follow-up visit for patients who were still alive. Chemotherapy toxicity was evaluated using National Cancer Institute Common Toxicity Criteria version 2.0.

\section{Results}

In all, 162 cycles were administered to 28 patients. There was no delay of therapy due to toxicity. In $6 / 28$ patients (21\%), chemotherapy was stopped after 2 cycles because the patients demonstrated PD in CT scan (4 patients) or deterioration of their performance status ( 2 patients). In most patients, therapy was stopped after the sixth cycle; however, 2 patients received 15 cycles until PD was noted and therapy was discontinued. Despite multiple repeated therapies, notable or dose-limiting toxicity never occurred in these patients. About $32 \%$ of the patients $(9 / 28)$ showed stable disease, while the remaining 13 patients $(46 \%)$ responded to therapy. Figure 4 A and B 

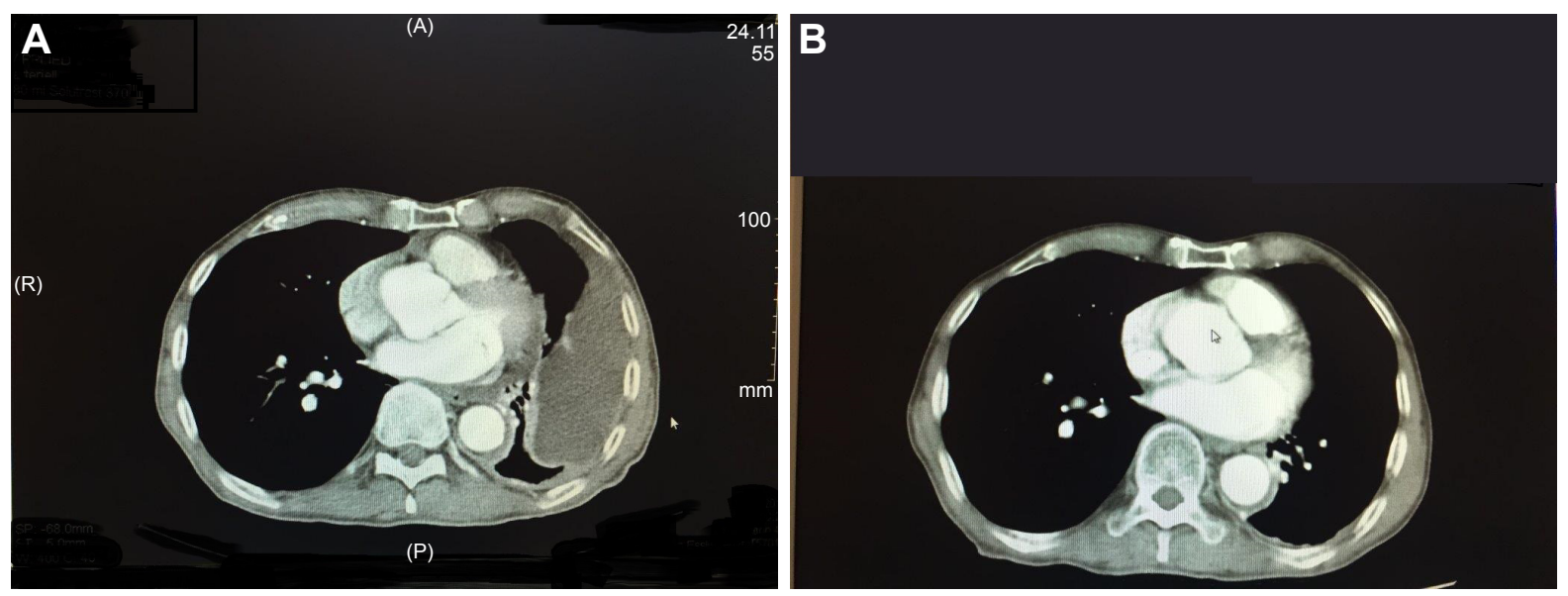

Figure $4 \mathrm{CT}$ scan with a complete response.

Notes: (A) CT scan of the chest of a male patient (76 years old) before therapy. Prior therapy consisted of VATS decortication and pleurodesis of the left lung and 2 cycles of cisplatin/pemetrexed. After this, progressive disease was diagnosed. (B) Complete disappearance of bulky lesions after the second course of isolated perfusion of the chest. Abbreviations: A, anterior; CT, computed tomography; P, posterior; R, right; VATS, video assisted thoracoscopic surgery.

presents a CT scan with a complete response after 2 cycles of isolated perfusion (chemotherapy).

\section{Survival}

Median survival was 12 months. One-year survival was 49\%, 2-year and 3-year survival was 31\%, and 5-year survival was $18 \%$ (Figure 5). Median PFS was 9 months, 1 year PFS was $37.5 \%$ (Figure 6).

\section{Toxicity}

Hematological toxicity was low with leucopenia and thrombocytopenia common toxicity criteria (CTC) grade I in 9 patients and mucositis grade I in 6 patients. Nausea and vomiting did not exceed CTC grade I in 12 patients. More than $95 \%$ of the patients suffered hair loss despite the application of a cool cap on the head during therapy. A transient phenomenon was facial edema, which occurred due to the high drug concentration during the stop-flow phase of the therapy. It persisted for 2-3 days but had no influence on the patient's QoL. Patients with borderline respiratory functions prior to therapy may need substitution of oxygen because of a slight interstitial edema during 2-3 days after therapy. In all cases, respiratory parameters improved after the second postoperative day. Surgical complications, CTC

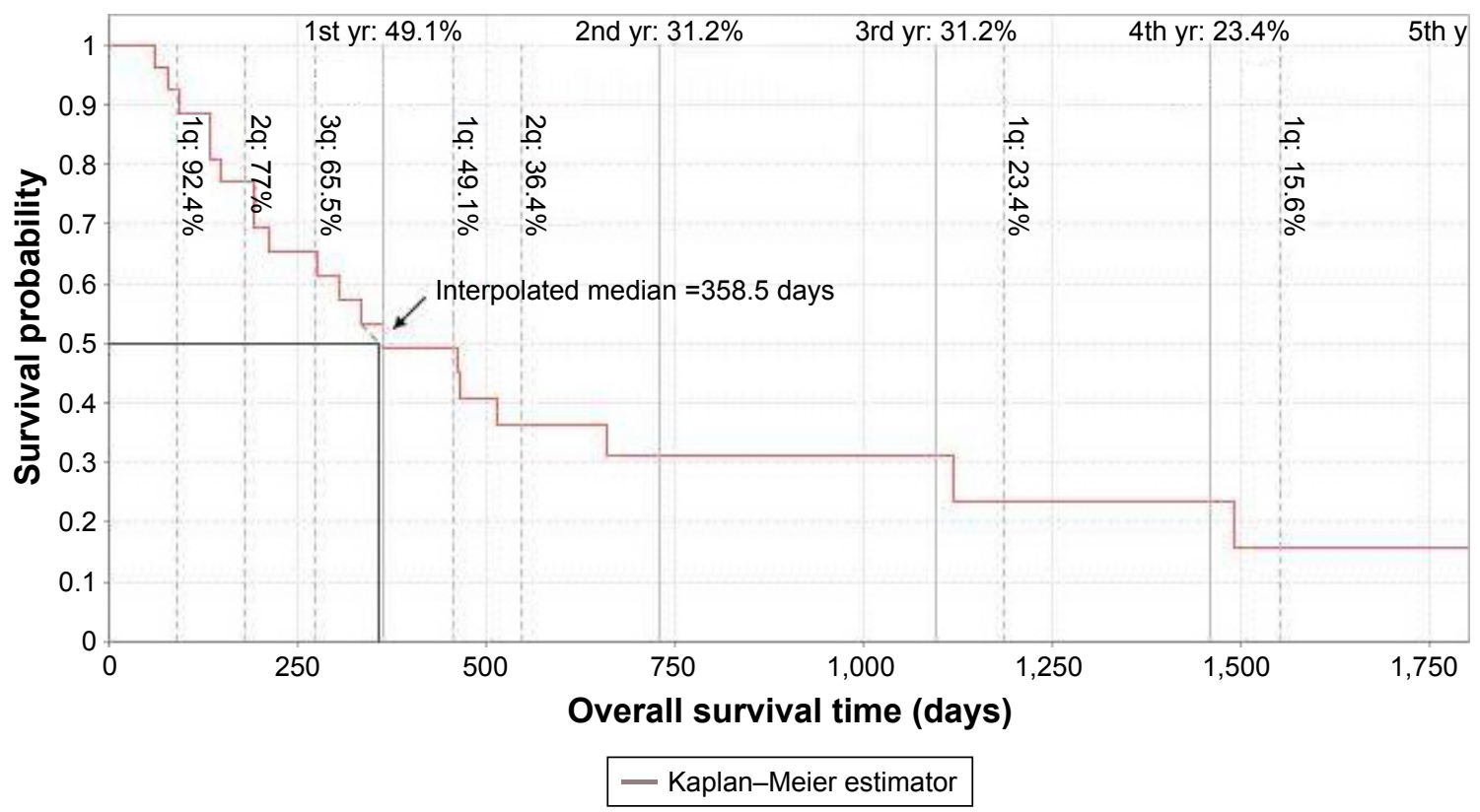

Figure 5 Kaplan-Meier plot of overall survival of all 28 patients.

Note: Median survival was 12 months, I-year survival was $49 \%$, and 2 -year and 3 -year survival was $31 \%$.

Abbreviation: yr, year. 


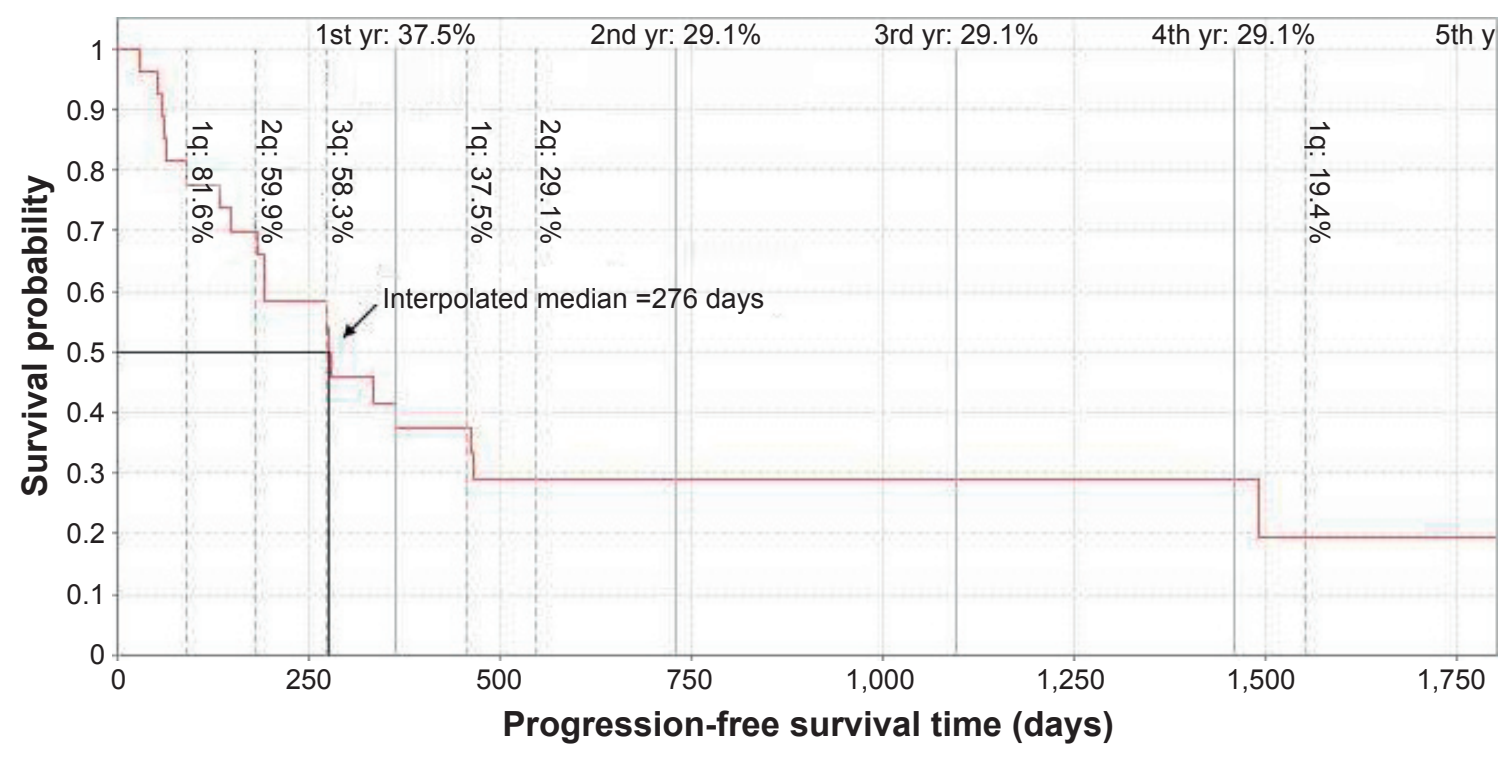

- Kaplan-Meier estimator

Figure 6 Kaplan-Meier plot of progression-free survival.

Note: Median progression-free survival was 9 months, I-year progression-free survival was 37.5\%, 2-year progression-free survival was $29 \%$. Abbreviation: yr, year.

grade I (lymphatic fistulas), occurred in $40 \%$ of the patients. This was the major therapy-related complication. It was treated by vacuum lymphatic drainage. No patient had to be reoperated due to lymphatic fistula. After 14 days at the most, the drainage could be removed.

Major toxicity $>$ CTC grade III or permanent liver or kidney damage never occurred. Toxicity from 15 minutes of hypoxia during treatment was noted in a slight elevation of the liver enzymes (maximum increase of 1.2-fold) and a slight elevation of serum creatinine. This was resolved at day 4-7 after therapy. All patients were discharged at least at day 5 after therapy. There was no gastrointestinal toxicity or neurotoxicity and no treatment-related death.

All patients who had prior systemic chemotherapy filled out a questionnaire comparing the 8 most common adverse events after systemic versus regional chemotherapy (RCT). It revealed an impressive advantage in favor of RCT as compared with conventional systemic administration. ${ }^{7}$

\section{Discussion}

MPM is a therapy-resistant disease for which there is no cure. Even in stage I and II, surgical intervention is merely a palliative procedure - even if major operations are performed - in a multimodal setting to minimize tumor burden. ${ }^{13}$ This is achieved with substantial morbidity and mortality from the extensive operations. ${ }^{14}$

Following that, multimodal approaches (bi- and trimodality) are currently being investigated in this group of patients. ${ }^{15} \mathrm{Up}$ to now, no substantial survival benefit could be achieved with these debilitating treatments. In the MARS trial, comparing EPP with no-EPP within a trimodal therapy, EPP did not add any benefit but rather caused side effects. With regard to the high morbidity and substantial mortality rate of a disease with short life expectancy the role of surgery remains questionable. ${ }^{6,16}$

Although there are no randomized trials comparing EPP with pleurectomy and decortication, historical controls on 3,101 patients revealed a survival advantage for EPP in stages I and II. ${ }^{17}$ Due to the malignant characteristics of mesothelioma, a near curative $\mathrm{R} 0$ resection is not considered sufficient to prevent relapse, but a resection of all surrounding tissues with potential microscopic lesions as an adjunct to adjuvant treatment modalities such as chemotherapy and/or radiotherapy is aimed at. ${ }^{5}$

However, the majority of patients with MPM are not candidates for curative surgery because of their low performance status, comorbidities, age, and the extent of the disease. Platinum-containing compounds revealed better efficacy than non-platinum-containing compounds. The administration of 3-drug compounds, however, did not show any advantage as compared to a 2-drug regimen. ${ }^{18}$ Interestingly, in first-line chemotherapy for unresectable disease, the combination of platinum-antifolate was superior to therapy with cisplatin alone, increasing overall survival by 3 months. The combination therapy increased overall survival to 12.1 and 11.4 months versus 9.3 and 8.8 months in the cisplatin-alone group, respectively. ${ }^{19,20}$ This short-term survival advantage, 
although statistically significant $(P$-value $=0.02$ and 0.048 , respectively), was accompanied by high-grade hematological and gastrointestinal toxicities.

The most recent randomized Phase III MAPS trial, however, comparing pemetrexed/cisplatin with (PCB) or without (PC) bevacizumab showed a significantly increased overall survival from 16.1 months in the PC arm to 18.8 months in the PCB arm. Grade III-IV adverse events, however, were significantly increased but manageable. ${ }^{21}$ Furthermore, toxicities are increased in elderly patients. The median age of patients with MPM ranges from 62 years in clinical trials to 74 years in routine clinical practice. ${ }^{22}$ Elderly patients are often not included and underrepresented in clinical trials. It has been described in a population-based epidemiological study that out of $37 \%(54 / 146)$ of patients with MPM declared suitable for chemotherapy, $52 \%$ declined this option and only $18 \%$ of the patients were randomized into chemotherapy trials, from our point of view the most fit for therapy patients, thus not representing the typical clinical problem. ${ }^{23}$ Elderly patients often cannot receive cisplatin-based chemotherapy due to reduced performance. The substitution of cisplatin by carboplatin is in widespread use. However, this is not supported by any randomized clinical trial. In a retrospective study of 210 patients $>70$ years of age, only $73 \%$ mainly received single drug chemotherapy with pemetrexed. The median overall survival was 11.3 months. ${ }^{24}$ Although pemetrexed-platinum is considered the standard first-line chemotherapy for pleural mesothelioma, only $\sim 50 \%$ of the patients respond to this therapy. Therefore, it is considered to provide no benefit in elderly patients with poor performance, especially, since no randomized trial has so far revealed any survival benefit from a second-line regimen. ${ }^{25}$

Several drugs and targeted therapies were investigated. ${ }^{26-28}$ Despite the fact that angiogenesis is an important factor in progressive mesothelioma, none of the antiangiogenic drugs tested so far could meet the requirements for being incorporated into standard clinical care. ${ }^{29,30}$

No second-line therapies met the expectations of the investigators, and it is still an unmet need in this patient population. Locoregional therapy could therefore be an additional option in this group of patients.

Locoregional chemotherapy is investigated in terms of hyperthermic intraoperative chemotherapy (HIOC) by several investigators. ${ }^{31-33}$ Despite the heterogeneity of the included patients and tumors, the authors reported that the demanding procedure including maximum surgical cytoreduction can be performed with acceptable morbidity and mortality. Sugarbaker et al report a longer interval to recurrence (27.1 vs 12.8 months) and significantly prolonged overall survival (35.3 vs 22.8 months). ${ }^{31}$ However, that was a nonrandomized Phase II study, and the patient groups were well balanced for prognostic factors. There is a strong imbalance in the number of patients treated with HIOC versus nontreated patients ( $\mathrm{n}=72$ vs 31 patients).

Looking at the existing data on various multimodal therapies, there is still a lack of therapies when conventional surgery, chemotherapy, and radiotherapy fail and result in PD. This gap, following this Phase II study, could be filled by the method of intra-arterial isolated perfusion with concomitant chemofiltration.

Although the patient population is heterogeneous in terms of pretreatment modalities, as is normal for such a study, the common basis of all investigated patients was treatment failure. For more or less all patients, the recommendation was best supportive care, resulting in a survival of 3-4 months.

An alternative method to isolation perfusion focuses on the high first-pass effect achieved with intra-arterial infusion. ${ }^{34}$ In this study, including 39 patients with nonoperable tumors, nonresponsive to systemic chemotherapy, infusion of the internal mammary or intercostal arteries via angiographically placed pigtail catheters generated local drug exposures, high enough to break through drug resistance of formally nonresponsive mesotheliomas. This study concentrates more on the feasibility of the method and determination of response. Side effects were low, although the reported "mean survival" rate of 15 months is not comparable with the generally used parameter "median survival", which was not reported in this study.

In this respect, the term "median survival" of 12 months, expressing the $50 \%$ survival rate, is a more meaningful parameter. Although the therapy did not - as all other treatments - result in a cure for the patients, it offers a good palliative option with low treatment-related toxicity and good QoL. Despite the high local drug exposure, RCT is better tolerated than systemic chemotherapy, first, because not the entire organism is exposed to chemotherapy and second because of the subsequent lowering of systemic drug exposure due to chemofiltration. A comparative study on QoL in patients who received RCTs after prior systemic chemotherapy revealed an impressive advantage in terms of QoL during RCT as compared to conventional systemic administration. ${ }^{7}$ Hospitalization of the patients was short As far as treatment modality is concerned, segmental isolation of the aorta at the level of the diaphragm in ITP allows a more homogeneous and equal drug distribution with high local concentration via all intercostal arteries. It has been shown in our study that an increase in local drug exposure translates into reasonable response rates in advanced and also 
heavily pretreated patients, ameliorating overall survival. It is of note that there can be a plateau phase in overall survival as the survival at 2 and 3 years is $37.5 \%$. This is an indication that there may be a subgroup of patients, which has a long-lasting benefit from the therapy. Interestingly, the 2- and 3-year survivor group included pretreated and non-pretreated patients.

Data relating to which group of patients really benefits can only be obtained in a larger study. Randomization of the patients after failure of all other strategies is rather unethical and not practical. If these data can be confirmed by a larger study, we might have a new armamentarium for the fight against this still threatening disease.

\section{Conclusion}

RCT in terms of ITP-F provides an additional modality to be used in the treatment of MPM. High drug concentrations are translated into reasonable response rates after repeated treatments. In this Phase II trial, locoregional chemotherapy was feasible and well tolerated. The toxicity profile was low, and the patients had a nearly normal QoL. Response rates and survival were encouraging with PFS of 9 months and median survival of 12 months in these heavily pretreated patients. Interestingly, 2-year and 3-year survival rates were $31.2 \%$ and $23.4 \%$ at 4 years. The data obtained are encouraging - though far from being satisfactory - and call for a potential improvement of application techniques, improvement of drug exposure, and an investigation of this method in a larger cohort of patients.

\section{Disclosure}

The authors report no conflicts of interest in this work.

\section{References}

1. Lee YC. Surgical resection of mesothelioma: an evidence-free practice. Lancet. 2014;384(9948):1080-1081.

2. van Zandwijk N, Clarke C, Henderson D, et al. Guidelines for the diagnosis and treatment of malignant pleural mesothelioma. J Thorac Dis. 2013;5(6):E254-E307.

3. Hiddinga BI, van Meerbeeck JP. Surgery in mesothelioma - where do we go after MARS? J Thorac Oncol. 2013;8(5):525-529.

4. Robinson BW, Musk AW, Lake RA. Malignant mesothelioma. Lancet. 2005;366(9483):397-408.

5. Kameda T, Takahashi K, Kim R, et al. Asbestos: use, bans and disease burden in Europe. Bull World Health Organ. 2014;92(11):790-797.

6. Mineo TC, Ambrogi V. Malignant pleural mesothelioma: factors influencing the prognosis. Oncology (Williston Park). 2012;26(12):1164-1175.

7. Aigner KR, Knapp N. Toxicity profiles with systemic versus regional chemotherapy. In: Aigner KR, Stephens FO, editors. Induction Chemotherapy - Systemic and Locoregional. 2nd ed. Berlin, Heidelberg: Springer-Verlag; 2016:497-506.

8. Aigner KR, Selak E. Isolated thoracic perfusion with chemofiltration (ITP-F) for advanced and pre-treated non-small-cell lung cancer. In: Aigner KR, Stephens FO, editors. Induction Chemotherapy. Berlin, Heidelberg: Springer; 2011:321-330.
9. Aigner KR, Gailhofer S, Schwarz M, Hilger N. Hypoxic abdominal perfusion for recurrent platin refractory ovarian cancer. Cancer Ther. 2008;6:213-220.

10. Guadagni S, Aigner KR, Palumbo G, et al. Pharmacokinetics of mitomycin $\mathrm{C}$ in pelvic stopflow infusion and hypoxic pelvic perfusion with and without hemofiltration: a pilot study of patients with recurrent unresectable rectal cancer. J Clin Pharmacol. 1998;38(10):936-944.

11. Guadagni S, Russo F, Abate G, et al. Stop-flow in mediastinum and thorax for resistant lymphoma. Hepatogastroenterology. 2000; 47(32):378-382.

12. Aigner KR, Müller H, Walther H, Link KH. Drug filtration in high-dose regional chemotherapy. In: Aigner KR, Patt YZ, Link KH, Kreidler J, editors. Regional Cancer Treatment. Vol 29. Basel: Karger; 1988:261-280.

13. Rusch V, Baldini EH, Bueno R, et al. The role of surgical cytoreduction in the treatment of malignant pleural mesothelioma: meeting summary of the International Mesothelioma Interest Group Congress, September 11-14, 2012, Boston, MA. J Thorac Cardiovasc Surg. 2013; 145(4):909-910.

14. Opitz I. Management of malignant pleural mesothelioma - the European experience. J Thorac Dis. 2014;6 (Suppl 2):S238-S252.

15. Shersher DD, Liptay MJ. Multimodality treatment of pleural mesothelioma. Surg Oncol Clin N Am. 2013;22(2):345-355.

16. Treasure T, Lang-Lazdunski L, Waller D, et al. Extra-pleural pneumonectomy versus no extra-pleural pneumonectomy for patients with malignant pleural mesothelioma: clinical outcomes of the Mesothelioma and Radical Surgery (MARS) randomised feasibility study. Lancet Oncol. 2011;12(8):763-772.

17. Rusch VW, Giroux D, Kennedy C, et al. Initial analysis of the international association for the study of lung cancer mesothelioma database. J Thorac Oncol. 2012;7(11):1631-1639.

18. Berghmans T, Paesmans M, Lalami Y, et al. Activity of chemotherapy and immunotherapy on malignant mesothelioma: a systematic review of the literature with meta-analysis. Lung Cancer. 2002;38(2):111-1121.

19. Vogelzang NJ. Chemotherapy for malignant pleural mesothelioma. Lancet. 2008;371(9625):1640-1642.

20. van Meerbeeck JP, Gaafar R, Manegold C, et al. Randomized phase III study of cisplatin with or without raltitrexed in patients with malignant pleural mesothelioma: an intergroup study of the European Organisation for Research and Treatment of Cancer Lung Cancer Group and the National Cancer Institute of Canada. J Clin Oncol. 2005;23(28):6881-6889.

21. Zalcman G, Mazieres J, Margery J, et al. Bevacizumab for newly diagnosed pleural mesothelioma in the Mesothelioma Avastin Cisplatin Pemetrexed Study (MAPS): a randomized, controlled, open-label, phase 3 trial. Lancet. 2016;387(10026):1405-1414.

22. Ceresoli GL, Grosso F, Zucali PA, et al. Prognostic factors in elderly patients with malignant pleural mesothelioma: results of a multicenter survey. Br J Cancer. 2014;111(2):220-226.

23. Chapman A, Mulrennan S, Ladd B, Muers MF. Population based epidemiology and prognosis of mesothelioma in Leeds, UK. Thorax. 2008;63(5):435-439.

24. Grosso F, Scagliotti GV. Systemic treatment of malignant pleural mesothelioma. Future Oncol. 2012;8(3):293-305.

25. Ceresoli GL, Zucali PA, Gianoncelli L, Lorenzi E, Santoro A. Secondline treatment for malignant pleural mesothelioma. Cancer Treat Rev. 2010;36(1):24-32.

26. Mansfield AS, Symanowski JT, Peikert T. Systematic review of response rates of sarcomatoid malignant pleural mesotheliomas in clinical trials. Lung Cancer. 2014;86(2):133-136.

27. Baas P, Buikhuisen W, Dalesio O, et al. A multicenter, randomized phase III maintenance study of thalidomide ( $\operatorname{arm} A$ ) versus observation (arm B) in patients with malignant pleural mesothelioma (MPM) after induction chemotherapy. In: ASCO Annual Meeting. J Clin Oncol. 2011;29.

28. Krug LM, Kindler HL, Calvert H, et al. Vorinostat in patients with advanced malignant pleural mesothelioma who have progressed on previous chemotherapy (VANTAGE-014): a phase 3, double-blind, randomised, placebo-controlled trial. Lancet Oncol. 2015;16(4):447-456. 
29. Remon J, Lianes P, Martinez S, Velasco M, Querol R, Zanui M. Malignant mesothelioma: new insights into a rare disease. Cancer Treat Rev. 2013;39(6):584-591.

30. Remon J, Requart N, Corral J, Lianes P. Malignant pleural mesothelioma: new hope in the horizon with novel therapeutic strategies. Cancer Treat Rev. 2015;41(1):27-34.

31. Sugarbaker DJ, Gill RR, Yeap BY, et al. Hyperthermic intraoperative pleural cisplatin chemotherapy extends interval to recurrence and survival among low-risk patients with malignant pleural mesothelioma undergoing surgical macroscopic complete resection. $J$ Thorac Cardiovasc Surg. 2013;145(4):955-963.
32. Bijelic L, Jonson A, Sugarbaker PH. Systematic review of cytoreductive surgery and heated intraoperative intraperitoneal chemotherapy for treatment of peritoneal carcinomatosis in primary and recurrent ovarian cancer. Ann Oncol. 2007;18(12):1943-1950.

33. Ried M, Potzger T, Braune N, et al. Cytoreductive surgery and hyperthermic intrathoracic chemotherapy perfusion for malignant pleural tumours: perioperative management and clinical experience. Eur $J$ Cardiothorac Surg. 2013;43(4):801-807.

34. Vogl TJ, Lindemayr S, Naquib NN, et al. Nonselective transarterial chemoperfusion: a palliative treatment for malignant pleural mesothelioma. Radiology. 2013;266(2):649-656.

\section{Publish your work in this journal}

OncoTargets and Therapy is an international, peer-reviewed, open access journal focusing on the pathological basis of all cancers, potential targets for therapy and treatment protocols employed to improve the management of cancer patients. The journal also focuses on the impact of management programs and new therapeutic agents and protocols on

\section{Dovepress}

patient perspectives such as quality of life, adherence and satisfaction. The manuscript management system is completely online and includes a very quick and fair peer-review system, which is all easy to use. Visit http://www.dovepress.com/testimonials.php to read real quotes from published authors.

\footnotetext{
Submit your manuscript here: http://www.dovepress.com/oncotargets-and-therapy-journal
} 